\title{
Can we implement the new research agenda for mental health?
}

Link to publication record in Manchester Research Explorer

\section{Citation for published version (APA):}

Lee, R. (2020). Can we implement the new research agenda for mental health? Nature Reviews Rheumatology, 16, 191.

\section{Published in:}

Nature Reviews Rheumatology

\section{Citing this paper}

Please note that where the full-text provided on Manchester Research Explorer is the Author Accepted Manuscript or Proof version this may differ from the final Published version. If citing, it is advised that you check and use the publisher's definitive version.

\section{General rights}

Copyright and moral rights for the publications made accessible in the Research Explorer are retained by the authors and/or other copyright owners and it is a condition of accessing publications that users recognise and abide by the legal requirements associated with these rights.

\section{Takedown policy}

If you believe that this document breaches copyright please refer to the University of Manchester's Takedown Procedures [http://man.ac.uk/04Y6Bo] or contact uml.scholarlycommunications@manchester.ac.uk providing relevant details, so we can investigate your claim.

\section{OPEN ACCESS}




\section{Can we implement the new research agenda for mental health?}

\section{Lis Cordingley@ and Rebecca Rachael Lee®}

\section{Children and young people with rheumatic diseases face considerable challenges to their mental health, yet the research guiding prevention and intervention strategies is limited. A new research agenda provides an important step forward by highlighting important issues, but can these research priorities be addressed within the paediatric rheumatology health-care context?}

\begin{abstract}
Refers to Rubinstein, T. B. et al. Prioritized agenda for mental health research in pediatric rheumatology from the Childhood Arthritis and Rheumatology Research Alliance Mental Health Workgroup. J. Rheumatol. https://doi.org/ 10.3899/jrheum.190361 (2020).
\end{abstract}

The management of childhood rheumatic diseases is complex; optimal quality care involves a multi-disciplinary approach covering a diverse range of professional practices, knowledge domains and skills, including medicine, nursing, physiotherapy, occupational therapy, social work, psychology and school liaison ${ }^{1}$. Arguably, responsibility for the emotional wellbeing of these young patients is shared by all members of the rheumatology team; however, there is currently little clear evidence about long-term outcomes on which to base clinical practice. Psychological distress functions as an outcome of disease as well as a contributor to the broader health of that individual $^{2}$.

The new agenda from the Childhood Arthritis and Rheumatology Research Alliance (CARRA) Mental Health Workgroup ${ }^{3}$, which outlines five broad priority domains of mental health research, is to be welcomed. As well as orientating researchers towards important gaps in our current knowledge and practice, it provides a timely reminder to everyone involved in commissioning health services of the need to keep psychological wellbeing at the heart of care provision. However, it is important to consider the research and healthcare context within which this new research agenda sits.

Research involving children and young people with chronic conditions faces very specific challenges, not least those that arise as a result of the major physical, intellectual, emotional and social changes that occur during childhood and adolescence. These challenges are seen most clearly when trying to interpret data from longitudinal cohort studies; arguably, one of the strongest methods available for paediatric rheumatology research. Additional methodological challenges relating to data collection from younger individuals include the use of proxies such as parents, who report on behalf of children but who are only able to provide partial representations of the child's wellbeing ${ }^{4}$, and a lack of data collection tools that are appropriate for the developmental stage of the child or young person. Even if these issues can be addressed, there is still a need to establish and maintain research cohorts large enough to develop robust, predictive models that can take account of the many other influences on health outcomes.
Acquiring a sufficiently large cohort is particularly challenging for rare rheumatic diseases and is further complicated when varied or complex treatment pathways need to be accounted for.

The first priority set out by the CARRA research agenda ${ }^{3}$ is to "determine the prevalence and incidence of mental health disorders in pediatric patients with rheumatological disease". Although some literature is available on the prevalence and incidence of psychological distress in young people with rheumatic diseases, it is of limited quality and quantity. Existing studies are predominantly cross-sectional, rather than longitudinal, and tend to include individuals with only the more common inflammatory rheumatic diseases such as juvenile idiopathic arthritis (JIA). Even within JIA research, limitations include a failure to link the incidence of mental distress with the rarer sub-types of JIA, where differences might be expected to arise. Characterizing the breadth of conditions is as important as characterizing the range of symptom severity within conditions and how they might or might not be associated with psychological distress. For example, paediatric rheumatology encompasses the treatment and management of inflammatory conditions, such as JIA, but also non-inflammatory conditions, such as hypermobility, complex regional pain syndromes and chronic back pain $^{5}$. Research into psychological outcomes across inflammatory and non-inflammatory conditions will be crucial for the identification of those mechanisms that are specific to inflammatory processes, as well as those that are associated with symptoms common to all conditions, such as persistent pain or fatigue.

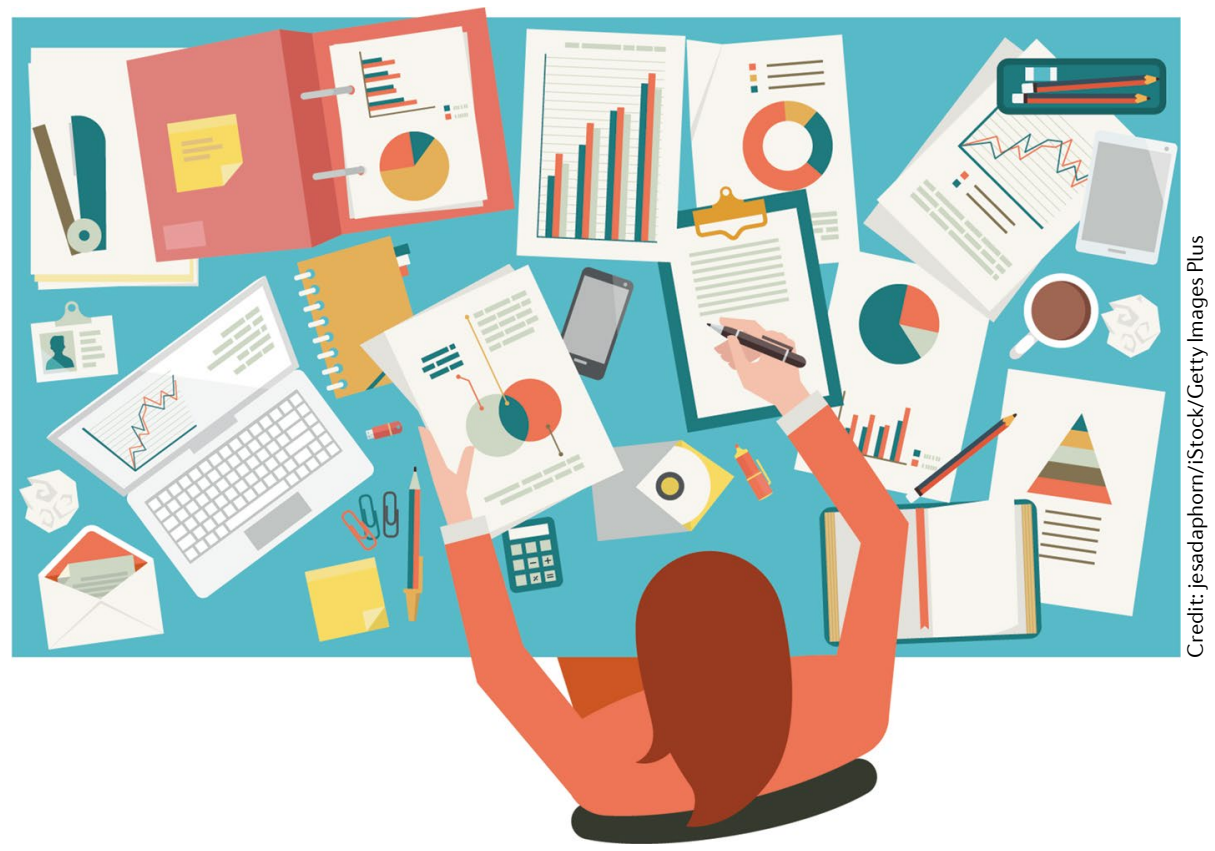


Importantly, mental health screening tools are not substitutes for conversations about mental health

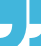

The routine capture of psychological data, which would require consensus building across both the research and clinical communities in terms of which variables to collect and when, would be one way to start to address the considerable gaps in our understanding of psychological wellbeing in childhood rheumatic diseases. In paediatric rheumatology research, consensus is already being achieved about data collection for physical aspects of disease $^{6}$. The emergence of new mobile and electronic health data collection methods will greatly enhance the availability of data for both research and clinical use.

Digital tools are often more acceptable to children and young people and less demanding than interviews or paper-based questionnaires ${ }^{7}$. Such tools might reduce the need for proxy reporting by parents or clinicians, as children as young as 5 years of age are able to directly provide data using digital tools. Furthermore, remote data collection frees up precious clinical consultation time.

Screening forms another important domain in the CARRA research agenda ${ }^{3}$. In practice, screening for mental health disorders in paediatric rheumatology varies considerably; some services use specific screening tools whereas others take a more general psychosocial interview approach ${ }^{8}$. Whether either approach has advantages in terms of prevention or identification of mental illness, or of other disease outcomes, is presently unclear. Importantly, mental health screening tools are not substitutes for conversations about mental health, and an approach that combines these methods might prove to be best.
Health-care professionals working in paediatric rheumatology are uniquely placed to postulate potential links between physical manifestations of the rheumatic disease and substantial changes in the psychological wellbeing of their patients; such changes are less likely to be picked up using generic mental health screening tools.

The nomenclature around mental health varies considerably between that used in the research literature and that used in clinical settings. Sometimes psychological distress is viewed as part of a broader concept, such as health-related quality of life ${ }^{9}$, and at other times specific disorders such as anxiety or depression are considered to be potential comorbidities of the rheumatic disease itself $^{10}$. Again, further consensus development around routine data capture would be beneficial; however, clarity is also needed about whether the focus should be on screening alone, or whether the research remit should be broadened to consider the prevention of psychological distress. With regards to prevention, the CARRA research agenda ${ }^{3}$ refers to "adjustment and coping interventions", rather than suggesting an explicit focus on the psychological processes that might contribute to the development of poor mental health for children and young people with rheumatic diseases. However, for such adjustment and coping interventions to be successful, relevant behavioural, cognitive or other psychological targets need to first be identified.

Overall, the CARRA prioritized agenda for mental health research in paediatric rheumatology $y^{3}$ provides an important steer for the research community. We need a research evidence base that will guide the development of interventions, not only to address the unmet mental health needs of young people with rheumatic diseases, but also to enhance management approaches that prevent mental illness and promote psychological resilience.
Lis Cordingley (D) ${ }^{\circledR}$ and Rebecca Rachael Lee (iD) ${ }^{2}$

${ }^{\prime}$ Division of Musculoskeletal and Dermatological Sciences, University of Manchester, Manchester, UK.

${ }^{2}$ Centre for Musculoskeletal Research, University of Manchester, Manchester, UK.

凶e-mail: Lis.Cordingley@manchester.ac.uk https://doi.org/10.1038/s41584-020-0399-z

1. Davies, K. et al. BSPAR standards of care for children and young people with juvenile idiopathic arthritis. Rheumatology 49, 1406-1408 (2010).

2. Davis, A. M. et al. Mental health care for youth with rheumatologic diseases - bridging the gap. Pediatr. Rheumatol. Online J. 15, 85 (2017).

3. Rubinstein, T. B. et al. Prioritized agenda for mental health research in pediatric rheumatology from the Childhood Arthritis and Rheumatology Research Alliance Mental Health Workgroup. J. Rheumatol. https://doi.org/10.3899/jrheum. 190361 (2020)

4. Varni, J. W., Limbers, C. A. \& Burwinkle, T. M. Parent proxy-report of their children's health-related quality of life: an analysis of 13,878 parents' reliability and validity across age subgroups using the PedsQL 4.0 Generic Core Scales. Health Qual. Life Outcomes 5, 2 (2007).

5. Clinch, J. \& Eccleston, C. Chronic musculoskeletal pain in children: assessment and management. Rheumatology 48, 466-474 (2009).

6. McErlane, F. et al. CAPTURE-JIA: a consensus-derived core dataset to improve clinical care for children and young people with juvenile idiopathic arthritis. Rheumatology 59, 137-145 (2020).

7. de la Vega, R. \& Miró, J. mHealth: a strategic field without a solid scientific soul. A systematic review of pain-related apps. PLoS One 9, e101312 (2014).

8. Doukrou, M. $\ltimes$ Segal, T. Y. Fifteen-minute consultation: communicating with young people - how to use HEEADSSS, a psychosocial interview for adolescents. Arch. Dis. Child. Educ. Pract. Ed. 103, 15-19 (2018).

9. Brunner, H. I. \& Giannini, E. H. Evidence-based medicine in pediatric rheumatology. Clin. Exp. Rheumatol. 18, 407-414 (2000).

10. Hanns, L. et al. Depressive symptoms, pain and disability for adolescent patients with juvenile idiopathic arthritis: results from the Childhood Arthritis Prospective Study. Rheumatology 57 1381-1389 (2018).

\section{Acknowledgements}

The work of the authors was supported by the National Institute for Health Research Biomedical Research Centre Funding Scheme and by the National Institute for Health Research Manchester Biomedical Research Centre. The views expressed in this publication are those of the authors and not necessarily those of the NHS, the National Institute for Health Research or the Department of Health. R.R.L. is in receipt of a Foundation Fellowship Award from Versus Arthritis UK (award number 22433).

\section{Competing interests}

The authors declare no competing interests. 